\title{
Consultor de viagens: o profissional do novo mercado turístico
}

\section{Travel consultant: the new touristic market professional}

\author{
Vanessa de Oliveira Menezes (MENEZES, V. de O.) ${ }^{*}$ e \\ Ana Paula Santos Staxhyn (STAXHYN, A. P.) ${ }^{* *}$
}

\begin{abstract}
RESUMO - As agências de turismo estão modificando suas formas de negócio e como comercializam seus produtos; isso se deve às transformações que a globalização e a evolução da tecnologia trouxeram para o mercado de viagens. Uma dessas formas é a consultoria de viagens, modalidade esta, que oferece conhecimento especializado e confiabilidade nas informações. A fim de oferecer contribuição sobre o assunto, o objetivo geral deste artigo é fazer uma discussão teórica acerca do tema consultoria de viagens, dando ênfase à figura do consultor. A metodologia aplicada neste estudo foi a de pesquisa bibliográfica, onde se buscou em livros, artigos, periódicos específicos da área de agenciamento e correlatos, o que foi produzido sobre o tema em questão. Os resultados obtidos mostraram que o consultor de viagens é uma evolução do agente de viagens. Que este profissional deve possuir habilidades e competências diferentes das esperadas pelos agentes e que esta modalidade precisa ser mais discutida e disseminada pelos gestores dos empreendimentos ligados ao mercado de viagens.
\end{abstract}

Palavras-chave: Agência de Turismo; Consultoria de Viagens; Consultor de Viagens.

ABSTRACT - The travel agencies are changing their ways of business and how they commercialize their products; that is due to the changes that the globalization and the technology evolution had brought to travel market. One of those ways is the travel consultancy, modality that offers specialized knowledge and reliable information. Seeking to provide a good contribution on the subject, the main goal of this article is make a theoretical quarrel concerning travel consultancy, emphasizing the consultant. The methodology used in this study was the bibliographical research, being used books, articles, specific journals of travel agency and related papers. The results had shown that the travel consultant is an evolution of the travel agent. So that, this professional must have different skills and competencies from those expected by the agents and then this modality needs to be more argued and spread by the managers of enterprises related to the travel market.

Key words: Travel Agency; Travel Consultancy; Travel Consultant.

\footnotetext{
* Graduação em Turismo pela Universidade Estadual do Oeste do Paraná (UNIOESTE), Campus Foz do Iguaçu. Especialização em Administração de Pessoas pela Universidade Federal do Paraná (UFPR). Mestrado em Administração de Empresas Turísticas pela Universidade de Extremadura - UEX (Espanha), revalidado pela Universidade Federal do Rio Grande do Norte (UFRN) e doutoranda em Administração pela Universidade Positivo. Professora do curso de Turismo na Universidade Estadual do Centro-Oeste (UNICENTRO), Campus Irati, Paraná. Endereço para correspondência: PR 153, KM 07. CEP: 84.500-000 Irati - Paraná (Brasil). Telefone: (41) 9917-4680. E-mail: vanessamenezes@ hotmail.com

** Graduação em Turismo pela Universidade Estadual do Centro-Oeste (UNICENTRO). Atuação profissional: Jornal Folha de Irati em Irati, Paraná. Endereço para correspondência: Rua Alfredo Nunes do Nascimento, 346 (Bairro Fósforo). CEP: 84.500-000 - Irati - Paraná (Brasil). Telefone: (42) 9937-5982; (42) 3422-6229. E-mail: ana_staxhyn@hotmail.com.br
} 


\section{INTRODUÇÃO}

O presente artigo trata sobre o profissional Consultor de Viagens. A Consultoria de Viagens está intimamente ligada às Agências de Turismo que são um importante canal de intermediação entre os produtos e serviços turísticos e o consumidor final.

Como efeito da globalização, os consumidores estão mais exigentes e informados, procurando constantemente pelo novo e por serviços de qualidade. (PETROCCHI e BONA, 2003). Montanarin (2002) complementa ao afirmar que essas pessoas não se contentam em apenas fazer uma viagem e sim surpreender-se com diferentes destinos. Desta forma, o trabalho do agente de viagens pode ser um importante fator para a conquista deste perfil de cliente. Uma vez que este profissional esteja preparado e munido de todas as informações acerca de um determinado local ou serviço, ele poderá contar com a fidelidade daquele consumidor.

Com base em Montanarin (2002), é possível afirmar que percebendo um novo perfil de turista, as agências de turismo estão oferecendo serviços diferenciados, entre eles a consultoria de viagens.

A consultoria de viagens é uma modalidade que vem se destacando no mercado atual. Isto se deve a diferentes fatores que influenciam nas formas de distribuição dos produtos e serviços turísticos, e nas formas de trabalho das agências de turismo e seus agentes de viagens. Esse fato mostra a importância de uma maior compreensão desta nova modalidade. Este novo serviço é oferecido por meio da figura do consultor, uma evolução do próprio agente de viagens.

No Brasil, a consultoria de viagens é ainda uma atividade recente e não são numerosos os profissionais ligados a esse setor que saibam exatamente o que é esse serviço e quais as características das pessoas que trabalham com este segmento. Muitos agentes de viagens ainda parecem acreditar que o simples atendimento ou a venda de um produto turístico caracteriza a consultoria.

A fim de oferecer uma contribuição sobre o assunto, o objetivo geral deste artigo é fazer uma discussão teórica acerca do tema consultoria de viagens, dando ênfase à figura do consultor. Para alcançar o objetivo proposto acima, o método de pesquisa adotado foi o de pesquisa bibliográfica, onde se buscou em livros, artigos, periódicos específicos da área de agenciamento e correlatos, o que foi produzido sobre o tema em questão, para assim fazer uma análise sobre o assunto. Foram pesquisados obras e autores tais como: o livro de 
Tomelin (2001); o de Petrocchi e Bona (2003); os capítulos de livro de Braga (2007), Lohmann (2007) e Santos (2007) e a monografia de Montanarin (2002) entre outros no período de abril a julho de 2010.

O presente artigo está dividido em 4 tópicos. O primeiro introduz o leitor ao tema, fazendo uma contextualização sobre o assunto, apresentando o objetivo e os procedimentos metodológicos para alcançá-lo.

O segundo discorre sobre as agências de turismo. Em um primeiro momento são apresentados conceitos, tipologias e atividades; posteriormente, é discutido sobre a situação atual das agências de turismo e por fim se apresenta o agente de viagens como peça fundamental para o sucesso deste tipo de empreendimento.

O terceiro descreve sobre o consultor de viagens, onde se discute sobre quem é esse profissional e quais suas atribuições. Neste tópico também são apresentados os requisitos necessários para trabalhar neste segmento, de acordo com a Norma N16 da Associação Brasileira de Normas Técnicas - ABNT.

E por fim, nas considerações finais se traz uma síntese de todos os temas abordados no texto.

\section{AGÊNCIAS DE TURISMO: CONCEITUAÇÃO, TIPOLOGIA E ATIVIDADES}

As agências de turismo são empresas responsáveis por assessorar o turista, ou seja, pelo seu deslocamento, pois prestam serviços e vendem produtos necessários para que o turista realize sua viagem. Uma agência de turismo trabalha com o atendimento ao público, organiza e promove pacotes turísticos disponibilizando uma gama de serviços ao consumidor final (DE LA TORRE, 2003).

Segundo o artigo 27 da Lei Geral do Turismo (BRASIL, 2008), documento que legisla sobre o funcionamento do turismo no Brasil consta que se "compreende por agência de turismo, a pessoa jurídica que exerce a atividade econômica de intermediação remunerada entre fornecedores e consumidores de serviços turísticos ou os fornece diretamente". E dispõe ainda sobre os serviços considerados de operação de viagens que são: "excursões e passeios turísticos, a organização, contratação e execução de programas, roteiros, itinerários, bem como recepção, transferência e a assistência ao turista". (BRASIL, 2008). 
Vários autores apresentam diferentes tipologias para as agências de turismo; Braga (2007) define as agências como sendo maioristas, aquelas que elaboram, planejam e organizam os produtos turísticos - conhecidas no mercado brasileiro como operadoras de viagens; e minoristas, que revendem os pacotes produzidos pela maiorista.

Já Acerenza, (1992, apud TOMELIN, 2001) ${ }^{1}$ inclui às agências citadas acima, as Agências de Viagens Tour Operators, onde estas operam seus programas com seus próprios equipamentos. Elas podem vender seus produtos às agências minoristas e aos consumidores. De acordo com o autor ainda têm-se as Agências de Viagens Receptivas, que são as que prestam serviços para as operadoras de turismo e às demais agências de turismo, oferecendo transfers, city tours e assessoria ao turista; por sua vez, as Agências de Viagens e Turismo Consolidadoras, que são agências que consolidam os serviços, repassando bilhetes aéreos às agências que não possuem o código IATA (International Air Transport Association). E por fim, as Agências de Viagens e Turismo Escola, que são empresas laboratório de instituições educacionais que desenvolvem as habilidades e competências dos futuros profissionais (TOMELIN, 2001).

Como base em Menezes (2009), os produtos e serviços comercializados nas agências de turismo são: venda de pacotes turísticos; venda de seguros viagem; auxílio com vistos e passaportes; venda de passagens aéreas, de trem e passagens rodoviárias; comercialização de diárias em meios de hospedagem; venda de cruzeiros marítimos; revenda de ingressos de espetáculos e demais eventos; aluguel de carro e consultoria de viagens.

Lohmann (2007) afirma que as agências de turismo apresentam três funções básicas: intermediação, operação e consultoria. A primeira, como o nome já explicita, faz a intermediação de serviços turísticos entre as agências e os clientes; a segunda função é na qual se planeja, organiza e vende os pacotes para atender os clientes, ressaltando que estes pacotes são diferentes dos vendidos pelas maioristas, esses são os chamados forfaits. Na terceira função, a agência presta informações detalhadas e aconselha seus clientes de forma a aumentar o conhecimento do turista com relação ao destino que vai conhecer.

Antes das inovações tecnológicas, principalmente do surgimento da Internet, as agências trabalhavam basicamente com duas das funções citadas acima, a de intermediação e a de operação. O cliente, já muitas vezes com sua ideia de viagem, se dirigia a uma agência para a organização da mesma. O agente de viagens, dentro de sua função,

\footnotetext{
${ }^{1}$ ACERENZA, M. A. Agencia de viajes. Organización y operación. México: Trillas, 1992.
} 
planejava a viagem, realizando a parte operacional, onde cuidava dos serviços básicos do produto turístico; o transporte, a alimentação e a hospedagem. O cliente saía da agência com a certeza de que sua viagem estava organizada e planejada.

Hoje esse cliente não quer somente esta certeza, ele deseja mais, ele quer a garantia de satisfação (MONTANARIN, 2002). Ele quer estar informado sobre como deve se portar, o que fazer, aonde ir; como é o clima da cidade, entre outros fatores que se farão necessários para deixar o consumidor seguro de que sua viagem será perfeita.

Este é o papel da agência, garantir que o passeio seja satisfatório, a partir do planejamento e organização do mesmo, proporcionando ao consumidor a segurança que os adventos tecnológicos sozinhos não lhe darão. É imprescindível lembrar que "uma viagem envolve várias etapas, que precisam ser harmonizadas para que dê tudo certo". (HOLLANDA, 2003, p. 3) Saber harmonizar um pacote turístico e atender às demandas do cliente devem ser os diferenciais de uma agência de turismo.

A partir do diferencial exigido hoje pelo mercado, entra-se numa fase de mudanças e evoluções, de aprimoramento e adequação por parte das agências que pretendem permanecer e crescer neste setor.

\footnotetext{
Diante de um novo cenário que se confirma, inclusive no Brasil, neste início de século XXI, em que seus principais fornecedores redefinem praticamente todas as características de seus negócios, das margens de lucro à utilização de novas tecnologias de gestão, participações de mercado e alianças estratégicas, as operadoras de turismo e as demais também reposicionam suas estratégias. (TOMELIN, 2001, p. 31).
}

O momento é de mudança, as agências de turismo e os agentes envolvidos precisam readequar-se ao novo perfil de seus clientes e traçar um caminho diferente impulsionados pelo mercado competitivo do setor de viagens. Acompanhar as novas características do mercado e de seus consumidores é um fator necessário para que as agências e os agentes de viagens permaneçam ativos na atividade turística. O que é possível ver hoje é uma nova realidade dentro das agências, pois elas estão reinventando suas formas de venda e distribuição do produto turístico, conforme será comentado no próximo item.

\subsection{REALIDADE DAS AGÊNCIAS DE TURISMO}

As agências de turismo fazem parte de um mercado cada vez mais competitivo, onde exercer somente a função de agenciamento de viagens (bloqueio e venda de bilhetes 
aéreos e terrestres, hospedagem, transportes e de alimentação) não satisfaz mais os consumidores atuais. Elas são responsáveis pela intermediação dos produtos e serviços, senão dos prestadores e fornecedores de serviços turísticos e os consumidores finais. Isso caracteriza as "agências como um importante canal de divulgação, distribuição e comercialização dos produtos e serviços turísticos”. (SANTOS, 2007, p. 43).

Ainda, segundo o mesmo autor, para realizar tal mediação, as agências eram comissionadas pelas empresas produtoras. Com a evolução tecnológica e as mudanças impostas pelo mercado de turismo, a intermediação passou a ser uma atividade menos lucrativa para as agências. Os consumidores puderam ter acesso a uma gama de informações e facilidades que antes eram disponibilizadas apenas pelas agências de turismo. Os fornecedores passaram a efetivar a venda dos produtos diretamente ao consumidor, acarretando uma redução e eliminação do comissionamento repassado às agências. Essa nova realidade é chamada de desintermediação.

A desintermediação acontece a partir da popularização da Internet, uma ferramenta essencial para o desenvolvimento da atividade, mas que junto com a inovação trouxe certa instabilidade para as agências de turismo, pois viram seu trabalho sendo disponibilizado por portais eletrônicos dos seus próprios fornecedores. As agências, então, passam de intermediárias a consultoras dos produtos e serviços turísticos. (SANTOS, 2007).

Mesmo com todas as facilidades que a Internet trouxe ao mercado atual, os clientes ainda procuram por algo que a rede de informações não oferece; o contato humano, a experiência, a atenção e a criatividade de profissionais especializados, que além de realizar todos os procedimentos da sua viagem, lhes orientem e lhes aconselhem com as mais variadas informações. (MONTANARIN, 2002).

\begin{abstract}
O impacto do surgimento da internet como ferramenta operacional e comercial associado à eventual desregulamentação do transporte aéreo e a demais fatores marcantes do final do século XX são desafios que o setor de viagens vem enfrentando no novo século, com efeitos no perfil do agente de viagens, marcado pela desintermediação dos serviços, pela reintermediação dos novos tipos de agências que estão surgindo e, objetivamente, pela alternativa de reposicionamento do seu perfil. (TOMELIN, 2001, p. 22).
\end{abstract}

A nova realidade das agências mostra que elas devem estar devidamente preparadas para atender pessoas cada vez mais conhecedoras e críticas de destinos turísticos. Profissionais qualificados e eficazes são o diferencial competitivo das agências, dentro de um mercado intensamente disputado e de clientes cada vez mais atualizados às tecnologias e as facilidades que os acompanham. 
O trabalho do agente de viagens torna-se então o diferencial de uma agência, pois ele deverá estar preparado para mostrar seus conhecimentos e seu profissionalismo, fazendo com que o cliente saia da empresa com uma bagagem de informações necessárias ao alcance da satisfação em sua viagem.

Neste momento as agências precisam promover uma reengenharia de suas formas de trabalho, revendo suas competências, a situação do mercado onde estão inseridas e os desejos dos clientes pelo novo para desta forma não perderem seu espaço para as tecnologias. (HOLLANDA, 2003). Mas é importante ressaltar que essas tecnologias devem ser vistas como ferramentas que ajudarão no desenvolvimento do trabalho dos agentes e não como um inimigo ou concorrente, pois elas têm vantagens e limitações em seu uso. Portanto, se bem utilizadas elas podem se tornar importante ferramenta para os profissionais e para os consumidores, mas que não comprometem o mercado das agências de turismo, e sim impõem novas relações de comunicação. (TOMELIN, 2001).

Além da tecnologia, as agências enfrentam outros problemas no mercado turístico. Crises econômicas, atentados terroristas, desvalorização cambial, entre outras situações, afetam diretamente o turismo e desestabilizam o segmento de viagens. (PONTES, 2005).

Tomelin (2001, p. 54) comenta que "quanto maior o grau de dificuldades externas impostas ao setor (recessão econômica, desvalorização cambial, redução do comissionamento, etc.), maior o acirramento da competição das empresas do segmento turístico".

No momento, há uma onda de informações circulando pelo mundo e sobre todos os assuntos. Para maior aproveitamento destas informações e melhor seleção das mesmas, surge a consultoria. O serviço de consultoria é uma forma de o cliente obter uma gama de informações pertinentes ao seu interesse, de forma segura, correta e com facilidade.

Como forma de reerguer-se e manter-se competitivos, os profissionais das agências constataram que o atendimento personalizado e a qualidade seriam fatores determinantes de seu papel no mercado turístico, uma vez que outros serviços, toda e qualquer agência poderia prestar. Mas a qualidade só se faria a partir do conhecimento e experiência adquirida pela agência e de seus agentes de viagens. (PONTES, 2005).

Cabe ressaltar neste momento, que a forma mais adequada que as agências encontraram para contornar os impasses do mercado e dos consumidores, foi a prestação de um serviço especializado, a consultoria de viagem. 
Segundo o Boletim Eletrônico Semanal do portal eletrônico Merkatus (2010, s/p):

A consultoria é um misto de conhecimento, muita informação, informação constantemente atualizada, empatia, percepção, sintonia interna e empatia, visão sistêmica, facilidade de encontrar caminhos e soluções, propensão e arte para a ação, [...] muito bom senso e muita facilidade de interação pessoal.

É importante salientar que há diferença com relação à consultoria de viagens e outros tipos de consultoria como a ambiental, a empresarial, a jurídica, a de gestão de pessoas, a turística etc. Pode-se usar como exemplo a consultoria empresarial, cujo conceito apresentado por Oliveira (2009, p. 185) é o de que corresponde a um:

[...] processo interativo de um agente de mudanças externo à empresa, o qual assume a responsabilidade de auxiliar os executivos e profissionais da referida empresa nas tomadas de decisões, não tendo, entretanto, o controle direto da situação.

Neste caso, a consultoria é dada a uma empresa/organização, a qual pretende solucionar problemas referentes ao seu funcionamento ou em outras situações. Já a consultoria de viagens é prestada ao cliente (consumidor), onde se pode interpretar como orientação e aconselhamento da melhor alternativa de viagem, e não somente resolução de problemas.

Parreira (1991, p. 12) define consultoria como "a arte de dar conselhos", e caracteriza essa atividade como uma troca de ideias e sugestões; um serviço de orientação; um trabalho especializado, com conhecimento técnico. Caracteriza também como uma atividade ética, passível de um controle de qualidade dos serviços prestados. O mesmo autor (p. 12) comenta ainda que "durante o serviço de consultoria, as duas partes, cliente e consultor, devem o tempo todo dar e pedir informações, fornecer e solicitar opiniões, um do outro". (PARREIRA, 1991, p. 12). Assim ocorre uma interação na consultoria, onde ambos mostram suas ideias e juntos buscam a melhor alternativa de viagem.

Não há um conceito ou definição própria para a consultoria de viagens, visto que é uma modalidade relativamente nova no Brasil e que ainda passa por aceitação por parte dos consumidores. Porém, é relevante ressaltar que há diferença entre consultoria de viagens e consultoria turística. A consultoria de viagens é aquela feita para auxiliar a distribuição e comercialização dos produtos turísticos, já a consultoria turística é voltada para o planejamento, em projetos e implantações de pólos turísticos. (MONTANARIN, 2002). 
$\mathrm{O}$ fato de as agências e os próprios agentes estarem se especializando e passando a trabalhar com a consultoria, acontece a partir da situação atual do mercado. A diminuição das comissões pagas às agências por serviços vendidos, como consequência, baixou a remuneração dos agentes, que precisam estabelecer novas políticas e cobrar taxas pela prestação do serviço, as chamadas fees. (MONTANARIN, 2002). A autora ainda explica que essa especialização é uma forma de justificar a cobrança das taxas nas vendas destes produtos ou serviços.

A consultoria, portanto entra como função de diferenciação entre um serviço disponibilizado pelas agências e a organização autônoma de uma viagem. A consultoria dada por uma agência de turismo ou pelo agente dá mais comodidade, principalmente aos clientes que não dispõem de tempo para realizar uma pesquisa detalhada de um destino e dos detalhes da viagem a ser feita.

Em tempos de competitividade acirrada, novas competências são exigidas dos profissionais de turismo, pois se deve lembrar que como cita Hollanda (2003, p. 7): "ainda que não possa ser experimentado antes da compra, o produto turístico deve satisfazer plenamente os sonhos dos mais exigentes consumidores". E essa é uma tarefa difícil, pois a satisfação total de um produto turístico é completamente relativa, considerando-se que este produto ou serviço é disponibilizado por pessoas para pessoas o que implica diretamente na qualidade da prestação do mesmo. (ARAÚJO, 2003).

É quase impossível prever como ocorrerá o atendimento ao turista após o início de sua viagem, pois este processo pode variar de local para local, como por exemplo, em um restaurante, o turista pode ser bem atendido e surpreendido, mas já no hotel algo pode ter sido feito de maneira não satisfatória para o hóspede, ou que os profissionais não lhe tenham dado a atenção merecida. Enfim, situações que não se podem prever, considerando que o atendimento é algo intangível e que a qualidade dele depende da ética profissional e do preparo daqueles que trabalham com esse tipo de atividade.

A partir do fato de que o atendimento com qualidade, feito pelos agentes de viagens, seria uma forma de diferenciar os serviços e produtos turísticos com relação aos de outras agências e que seria um fator decisivo para maior obtenção de confiabilidade por parte dos consumidores, é que deve ser destacado o trabalho do agente de viagens, o qual é peça importante na distribuição e comercialização dos serviços turísticos. 
O agente de viagens é o profissional responsável pela intermediação entre os fornecedores e consumidores finais; ele apresenta, de acordo com o desejo do cliente, os produtos turísticos de uma agência.

\subsection{O AGENTE DE VIAGENS}

O trabalho de um agente de viagens é essencial para o sucesso de uma agência, porque é ele quem fará o primeiro contato com o cliente e apresentará os produtos e serviços oferecidos por sua empresa.

Dantas (2002, p. 48) afirma que:

\footnotetext{
O agente de viagens é um profissional com a função de apresentar o produto turístico ao cliente, ou vice-versa, fornecendo informações, aconselhamentos e, modernamente, assessoria e consultoria em viagens, ou seja, um intermediário.
}

A função de intermediadora dada às agências de turismo também pode ser atribuída ao agente de viagens, considerando que é ele quem mantém um relacionamento direto com os clientes da agência.

Antes da chegada da Internet, De La Torre (2003) comenta que o trabalho dos agentes de viagens consistia em vender serviços básicos que compõem o setor do turismo, ou seja, emissão de bilhetes aéreos e terrestres, constituindo o transporte, a reserva de hospedagem e o atrativo turístico. As agências de turismo eram pequenas empresas e que não exigiam muitas atribuições de seus atendentes, hoje muitos chamados de agentes. Como o fluxo de passageiros não era grande, os agentes se especializavam para atender às necessidades de seus clientes. (MONTANARIN, 2002).

Contudo, o papel dos agentes vem se modificando e se adaptando às diversas mudanças que o contexto atual de consumidores vem propondo; o de um profissional especializado, experiente e que lhe ofereça informação e conhecimento, passando a ser o diferencial competitivo das agências e atraindo consumidores que desejam ser informados com plenitude. Este profissional está sendo forçado a se transformar em muito mais que intermediador ou vendedor de um produto ou serviço. (PONTES, 2005). Todas as mudanças e evoluções estão fazendo com que os agentes se transformem em conselheiros que auxiliarão na obtenção de satisfação do cliente e não somente de venda para o mesmo. 
Em geral, as competências dos agentes de viagens continuam sendo as mesmas de antes, o planejamento e organização de viagens, mas agora com ênfase na qualidade do atendimento e ampliação de seus conhecimentos e capacidade de inovação e criação de estratégias que venham a atender, conquistar e fidelizar os clientes.

A partir deste novo cenário, os agentes devem atentar-se para como devem se comportar diante dos novos consumidores, fortalecendo suas habilidades interpessoais. Possuindo essas atribuições e esse diferencial, é que o agente evolui surgindo um novo profissional, o consultor de viagens.

Este novo profissional oferece aos clientes muito mais que apenas a intermediação e a organização de viagens; ele tem conhecimento e experiência suficiente para dar aconselhamento e pareceres dos locais desejados por seus clientes. Além de organizar a viagem, ele dará um suporte de detalhes dos destinos turísticos inerentes ao alcance da satisfação e qualidade da viagem.

\section{O CONSULTOR DE VIAGENS}

A função do consultor é a de auxiliar o cliente em suas escolhas, mostrando-lhe o melhor caminho e melhor aproveitamento da viagem. Merron (2007, p. 5) confirma este pressuposto quando discorre que "na essência de qualquer atividade de consultoria está o desejo, por parte do cliente, de ter ajuda, e do consultor, de oferecê-la".

O consultor de viagens deve disponibilizar informações detalhadas sobre o assunto em que é especializado, possuir um conhecimento mais aprimorado e deve possuir experiências que vão passar credibilidade aos clientes no momento da consultoria. Pode-se dizer que o consultor de viagens é uma evolução dos agentes de viagens. O profissional "consultor de viagens" ainda não tem amplo reconhecimento no Brasil, principalmente por parte dos consumidores que em um primeiro momento não conseguem diferenciá-los dos agentes de viagens, mas nos Estados Unidos e em muitos países da Europa essa função já é bastante valorizada. (MONTANARIN, 2002).

Para ser considerado um consultor, o profissional deve possuir capacitação e habilidades. Tomelin (2001) apresenta três habilidades que o consultor deve possuir, sendo elas:

- Técnica, a parte operacional do agenciamento (conhecer os sistemas, bilhetes, vendas etc.); 
- Relacionamento, que são as habilidades interpessoais, onde ele aconselha e aperfeiçoa as ideias de seus clientes e;

- Conhecimento, habilidades da própria consultoria.

Portanto, é um profissional que não realiza somente a venda de um produto; ele dá orientação ao cliente, assessora, aconselha e mostra qual a melhor alternativa, ou qual o melhor destino, dentro dos desejos e perfil do cliente, diferenciando-se do seu antecessor, o agente de viagens. Luiz (2009) complementa mencionando que o consultor de viagens necessita ter conhecimento máximo dos destinos, dos pontos turísticos e de tudo que é essencial e acessório em uma viagem, visando agregar valor ao seu serviço.

"Este conceito de orientação sugere que o consultor não deve controlar o cliente nem a situação. Fazer isso não agregaria valor. Em vez disso, o consultor capacita, ensina, orienta ou facilita”. (MERRON, 2007, p. 107)

O termo consultor, quando relacionado a viagens, ainda não é muito encontrado, por se tratar de uma função que está em fase de crescimento e assimilação por parte dos consumidores. Embora esta profissão esteja em fase de reconhecimento e valorização, problemas são gerados com relação ao profissional e suas atribuições. Alguns profissionais estão usando o termo “consultor" sem possuir a especialização necessária para esta função, e muitas vezes, sem saber qual o real significado da mesma. Por outro lado, aqueles profissionais que são especializados e possuem experiências para desempenhar tal função não estão sendo devidamente reconhecidos (MONTANARIN, 2002).

É importante ressaltar que um bom consultor não deve ser somente especializado no conhecimento e na prestação de informações a respeito de viagens e outros tipos de serviços inerentes, mas sim estar atualizado com todos os softwares e programas GDS Global Distribution System, para a prestação completa do serviço ao cliente. (MONTANARIN, 2002). O consultor poderá realizar todos os procedimentos que um agente de viagens realiza na hora da venda de destinos e pacotes turísticos, agregando valor ao serviço prestado com suas experiências e conhecimentos.

Para facilitar o entendimento do perfil e das competências que um consultor necessita ter para que seja designado como tal, o Projeto de Norma N16 da Associação Brasileira de Normas Técnicas - ABNT (2008), elaborado no âmbito dos Comitês Brasileiros (ABNT/CB) e Organismos de Normalização Setorial (ABNT/ONS), estabelece os resultados esperados e as competências para este profissional. Esta norma define que um consultor de viagens "ocupe-se, principalmente, de captar e fidelizar novos clientes, a 
partir de um atendimento diferenciado, de forma a garantir a sustentabilidade do negócio". (ABNT, 2008, p. 1).

Em suma, o projeto de norma mostra que o consultor deve além de realizar as atividades já desempenhadas pelo agente de viagens, ser capaz de escolher fontes adequadas de pesquisa e localização de informação desejada; avaliando, selecionando e transformando essas informações em conhecimentos; extrair aprendizagem das próprias experiências; participar de palestras, seminários, cursos de treinamento, eventos do ramo e viagens técnicas.

Outra característica mencionada pela norma é de que os consultores devem saber criar e inovar, gerando ideias que agreguem valor ao negócio; operacionalizar essas ideias utilizando-se de alternativas inovadoras em oposição aos métodos e enfoques tradicionais; enfim sendo um agente de mudanças, vencendo os obstáculos necessários.

Um bom consultor deve participar da definição de políticas de qualidade, mantendo-as e melhorando-as, criando diferenciais nos seus serviços; manter o controle sobre o desempenho de produtos, serviços e processos da empresa. Além disso, deve operacionalizar produtos turísticos, incluindo a confirmação de produtos e serviços, informando detalhadamente os componentes da viagem e assessorar o cliente na documentação de viagem. (ABNT, 2008).

A ABNT ainda propõe que o consultor de viagens deve observar e executar as estratégias de vendas e políticas comerciais da empresa, fornecendo informações e assessoramento ao cliente sobre destinos, serviços, produtos, tarifas, taxas, prazos e validade.

Para que se realize um bom negócio é necessário manter uma rede de parceiros e fornecedores, identificando e selecionando criteriosamente para contratar fornecedores idôneos, que garantam a qualidade dos produtos e serviços. O consultor deve, portanto, estabelecer parcerias; atender e visitar esses parceiros e fornecedores e procurar manter extensa e qualitativa a rede de contatos. (ABNT, 2008).

O consultor deve prestar consultoria de viagens ao cliente, promovendo a captação de novos públicos. Deve conhecer em profundidade os locais e produtos que compõem os pacotes turísticos comercializados. Deve compreender as singularidades daqueles que procuram seus serviços para oferecer soluções adequadas e idôneas para satisfazer as necessidades do cliente, excedendo suas expectativas. 
Deve orientar com informações diferenciadas e referências especiais de um destino, agregando serviços e produtos proporcionando experiências diversificadas ao cliente e saber avaliar a satisfação do mesmo pelos serviços prestados pela empresa e fornecedores.

Além das competências acima descritas, o consultor deve estar atualizado com informações sobre turismo em âmbito local, regional, nacional e mundial; sobre os diversos serviços do turismo e especialmente do segmento de agenciamento e operações turísticas; deve atentar-se para as novas técnicas de vendas; na atual legislação turística e código de defesa do consumidor; nas características de produtos e serviços comercializados; nos principais aspectos histórico-geográficos, culturais, sócioeconômicos e legais dos principais destinos turísticos (ABNT, 2008).

\section{CONSIDERAÇÕES FINAIS}

A partir do que foi apresentado no artigo, considera-se ser possível compreender que as inovações tecnológicas vêm contribuindo para a evolução do mercado turístico, principalmente do setor de viagens. A chegada da Internet revolucionou a forma de trabalho das agências de turismo e consequentemente contribuiu para a mudança do perfil dos agentes que nelas trabalham.

Os agentes de viagens se especializaram para atender um público cada vez mais exigente e crítico, conhecedor de muitas informações disponibilizadas pela Internet. A partir disso, os profissionais passaram a dar um suporte maior de informações e detalhes de viagens, antes não fornecidos para os clientes, o que se caracterizou como um serviço diferencial prestado pelas agências.

Essa mudança na forma de venda dos produtos e serviços turísticos ocorreu também pela desintermediação na distribuição dos serviços; ou seja, quando as companhias aéreas e operadoras diminuíram seus comissionamentos às agências, já que podiam efetuar suas vendas diretamente aos consumidores pelos seus próprios canais de distribuição (pontos de vendas e sites). Essa nova realidade fez com que surgisse um novo profissional, o consultor de viagens, que oferece uma nova forma de venda por meio da consultoria.

A prestação de consultoria é uma maneira para captar e fidelizar os clientes e manter-se no mercado de viagens, que hoje continua em mutação pela consequente globalização. 
A consultoria é a forma mais completa do cliente obter as informações necessárias para alcançar a satisfação de sua viagem. Por meio dela, ele obterá informações imprescindíveis dos consultores para escolher o melhor destino de acordo com o perfil do cliente, além de oferecer informações úteis como detalhes do local, clima, moeda, como vestir-se, aonde ir, o que fazer em determinados locais, onde fazer compras, onde descansar, entre outros detalhes inerentes à viagem.

Essa nova modalidade de venda está diretamente ligada ao bom atendimento e qualidade na prestação de serviços. Um agente de viagens vende um produto, já o consultor além de vender, oferece alternativas e conselhos ao seu cliente mostrando-lhe qual o melhor destino e qual a melhor maneira de realizar a viagem.

Como já visto a partir da Norma N16 da ABNT (documento que estabelece as competências do consultor de viagens), o consultor possui funções que antes não eram atribuídas aos agentes de viagens, transformando-o em um profissional completo. $\mathrm{O}$ agente revende um produto/serviço, planeja e organiza uma viagem, mas sem a sensibilidade de um consultor. Este sim deve se dedicar ao máximo no momento de apresentar um destino ao seu cliente, mostrando-lhe as vantagens e desvantagens; os melhores lugares dentro das expectativas do turista etc. Ele vende seu conhecimento e sua experiência garantindo a satisfação na compra da viagem.

A função dos agentes de turismo é mais técnica, concentrada na operacionalização de uma viagem; já os consultores, além desse conhecimento técnico, devem possuir habilidades interpessoais, onde conseguem entender o cliente, perceber os desejos do mesmo, vendendo produtos e serviços que se identificam com ele.

Um consultor deve ser além de um profissional técnico, um bom vendedor, ou seja, aquele que sabe oferecer o produto que se identifica com o consumidor; aquele que busca preço competitivo com qualidade; que possui empatia e que seja ótimo observador para perceber e entender o perfil de seus clientes para vender a eles produtos que eles querem comprar.

Um profissional que só vende não é completo, ele precisa entender seus clientes, possuir qualidades como ser simpático, gentil, aquele que escuta até o final, deixando o consumidor mostrar qual é sua expectativa, que se especializa em atender às necessidades das pessoas.

Vale lembrar que este profissional deve possuir todas essas qualidades além das habilidades técnicas já evidenciadas neste trabalho. 
Conclui-se que a consultoria ainda precisa ser mais bem entendida pelo mercado e pelos profissionais que trabalham na linha de frente das agências. Alguns gestores têm consciência dessa prática, mas ainda não a passam aos seus colaboradores. Essa modalidade também precisa ser mais conhecida pelo mercado consumidor, pois é o que mais se beneficiará com este novo serviço.

\section{REFERÊNCIAS}

ABNT - ASSOCIAÇÃO BRASILEIRA DE NORMAS TÉCNICAS. Norma N16, 2008. Disponível em: <http://www.abnt.org.br>. Acesso em: 31/05/2010.

ARAÚJO, C. M. Ética e qualidade no turismo do Brasil. 1. ed. São Paulo: Atlas, 2003.

BRAGA, D. C. Discussão Conceitual e Tipologias das Agências de Turismo. In:

(Org.) Agências de viagens e turismo: práticas de mercado. São Paulo: Campus, 2007, p. $18-28$.

BRASIL. Ministério do Turismo. Lei Geral do Turismo, n. 11.771, de 17 de setembro de 2008. Disponível em: <http://www.turismo.gov.br>. Acesso em: 11/04/2010.

DE LA TORRE, F. Agências de viagens e transporte. São Paulo: Roca, 2003.

DANTAS, J. C. de S. Qualidade do atendimento nas agências de viagens: uma questão de gestão estratégica. São Paulo: Roca, 2002.

HOLLANDA, J. Turismo: operação e agenciamento. Rio de Janeiro: SENAC Nacional, 2003.

LOHMANN, G. A tecnologia e os canais de distribuição em turismo. In: BRAGA, D. C. (Org.). Agências de viagens e turismo: práticas de mercado. São Paulo: Campus, 2007, p. $30-41$.

LUIZ, V. R. O atual papel das agências de viagens no mercado de turismo brasileiro, 2009. Disponível em: <http://www.artigonal.com/turismo-artigos/o-atual-papel-dasagencias-de-viagens-no-mercado-de-turismo-brasileiro-1259594.html>. Acesso em: 07/04/2010.

MENEZES. V. de O. Agenciamento de Viagens. Mimeo., 2009.

MERKATUS. Boletim eletrônico semanal. Disponível em: 〈www.merkatus.com.br〉. Acesso em: 01/06/2010.

MERRON, K. Dominando consultoria: como tornar-se um consultor master e desenvolver relacionamentos duradouros com seus clientes. São Paulo: M. Books, 2007. 
MONTANARIN, D. C. Consultor de viagens: novo profissional da era do conhecimento. Curitiba. Monografia (Especialização), Pontifícia Universidade Católica do Paraná, Curitiba, 2002.

OLIVEIRA, D. de P. R. Manual de consultoria empresarial: conceitos, metodologia, práticas. 8. ed. São Paulo: Atlas, 2009

PARREIRA, F. E. Consultoria: consultores e clientes. São Paulo: Érica, 1991.

PETROCCHI, M.; BONA, A. L. V. Agências de turismo: planejamento e gestão. São Paulo: Futura, 2003.

PONTES, A. S. M. A consultoria como estratégia de qualidade para os serviços das agências de viagens e turismo da cidade de Caçador, SC. Monografia. Universidade do Contestado (UNC), 2005. Disponível em: $<$ http://www.etur.com.br/conteudocompleto.asp?idconteudo=8489>. Acesso em: 07/04/2010.

SANTOS, C. M. Os processos de intermediação, desintermediação, reintermediação e seus reflexos sobre a remuneração das agências de turismo. In: BRAGA, D. C. (Org.). Agências de viagens e turismo: práticas de mercado. São Paulo: Campus, 2007, p. 42-54.

TOMELIN, C. A. Mercado de agências de viagens e turismo: como competir diante das novas tecnologias. São Paulo: Aleph, 2001.

Recebido em: 28-04-2011.

Aprovado em: 28-05-2011. 